\title{
Trends and temperature sensitivity of moisture conditions in the conterminous United States
}

\author{
Gregory J. McCabe ${ }^{1, *}$, David M. Wolock ${ }^{2}$ \\ ${ }^{1}$ US Geological Survey, Denver Federal Center, MS 412, Denver, Colorado 80225, USA \\ ${ }^{2}$ US Geological Survey, 4821 Quail Crest Place, Lawrence, Kansas 66049, USA
}

\begin{abstract}
Observed (1895-1999) trends in climatic moisture conditions in the conterminous United States (US) characterized by (1) annual precipitation minus annual potential evapotranspiration (PMPE), (2) annual surplus (water that eventually becomes streamflow), and (3) annual deficit (the amount of water that must be supplied by irrigation to grow vegetation at an optimum rate) are examined. The sensitivity of moisture conditions across the conterminous US to increases in temperature also are examined. Results indicate that there have been statistically significant trends in PMPE, annual surplus, and annual deficit for some parts of the conterminous US. Most of the significant trends in PMPE have been increasing trends primarily in the eastern US. Annual surplus also has increased over the eastern US, whereas the magnitudes of annual deficit have decreased. For the conterminous US as a whole, there has been a statistically significant increase in PMPE and annual surplus; however, there is no significant trend in annual deficit. Results also indicate that PMPE and annual deficit in the warmest regions of the conterminous US are most sensitive to increases in temperature. The high sensitivity of PMPE and annual deficit in these regions to increases in temperature is related to the relation between temperature and the saturation vapor pressure of air. The increases in potential evapotranspiration for a given change in temperature are larger for high temperatures than for low temperatures. The regions with the highest sensitivity of annual surplus to increases in temperature are the humid regions of the country. In these regions, annual surplus is large and increased potential evapotranspiration, resulting from increased temperature, has a significant effect on reducing annual surplus. In the dry regions of the country, annual surplus is so low that increases in potential evapotranspiration only result in small decreases in annual surplus.
\end{abstract}

KEY WORDS: Moisture index $\cdot$ Climate change $\cdot$ Global warming

\section{INTRODUCTION}

There is concern that increasing concentrations of atmospheric carbon dioxide and other radiatively active gases may cause global warming and changes in temporal and spatial distributions of precipitation and, subsequently, adversely affect water resources (Gleick 1987, Lettenmaier \& Sheer 1991, Wolock \& McCabe 1999b). To examine the effects of climate change and variability on water resources in the conterminous United States (US), there have been numerous studies to identify historical trends in observed

*E-mail: gmccabe@usgs.gov temperature, precipitation, and runoff (e.g. Solow 1987, Karl \& Riebsame 1989, Karl et al. 1989, Solow \& Broadus 1989, Lins \& Slack 1999). There also have been numerous studies of the hydrologic effects of climate change in the conterminous US (Nemec \& Schaake 1982, Idso \& Brazel 1984, Wigley \& Jones 1985, Mather \& Feddema 1986, Gleick 1987, 1989, Karl \& Riebsame 1989, McCabe \& Ayers 1989, Lettenmaier \& Gan 1990, Schaake 1990, McCabe \& Wolock 1991, Nash \& Gleick 1991, Wolock \& Hornberger 1991, Ayers et al. 1994, McCabe \& Hay 1995, Wolock \& McCabe 1999a,b). These studies have indicated historical trends in important hydroclimatic variables and have presented potential hydrologic consequences of climate change. Most of these studies, however, primarily 
addressed the effects of climate change on water resources for individual river basins. There have only been a few studies that have addressed the effects of climate change across large regions with a focus on identifying the sensitivity of particular regions to climate change, particularly to increases in temperature (McCabe \& Wolock 1997).

Moisture conditions are an important hydrologic characteristic sensitive to climatic variability. Moisture conditions have been quantified by indices that describe the relation between the climatic supply of water (precipitation) to the climatic demand for water (potential evapotranspiration, PE) (Thornthwaite 1948, Thornthwaite \& Mather 1955, Budyko 1974, Mather 1978, Willmott \& Feddema 1992, Milly 1994). Two of the oldest and most frequently used moisture indices are those developed by Thornthwaite (1948) and Budyko (1955). Thornthwaite developed one of the first moisture indices and used it to generate a climate classification for the US. In addition to climate classification, the Thornthwaite moisture index has been used to describe relations between climate and soils and vegetation types, and has been used in studies of the effects of climate change on moisture conditions (Mather 1978, McCabe \& Wolock 1991, 1992, Feddema \& Mather 1992). Budyko $(1955,1974)$ and Milly (1994) used a simple moisture index which they termed the index of dryness. This index of dryness is defined simply as the ratio of PE to precipitation. Budyko used this index to develop a climate classification for the world.

Because moisture indices are indicators of a region's moisture conditions and are related to important water resources such as runoff (Wolock \& McCabe 1999a), they are useful for the study of the effects of climate variability and change on the hydroclimate of a region (McCabe \& Wolock 1991，1992, Feddema \& Mather 1992). In this study, (1) empirical moisture indices are used to identify observed long-term trends in moisture conditions across the conterminous US, and (2) because of concern about global warming, the moisture indices are used to examine the sensitivity of moisture conditions to prescribed increases in temperature.

\section{METHODS}

2.1. Moisture indices. In a study of the hydrologic concepts needed in a water-balance model to estimate the spatial variability in mean annual runoff, Wolock \& McCabe (1999a) determined that $91 \%$ of the spatial variability of mean annual runoff for the climate divisions of the conterminous US was explained by the spatial variability of mean annual precipitation minus mean annual potential evapotranspiration (PMPE). This simple index of the climatic supply of water relative to the climatic demand for water serves as a useful index of relative moisture conditions from one region to another. For the present study, this simple index was chosen as an indicator of moisture conditions because (1) it has been shown to be related to annual runoff and (2) it is simple to compute and to interpret. Positive values indicate that the climatic supply of water is greater than the climatic demand, and negative values indicate that the climatic demand for water is greater than the climatic supply. In addition, this index is more linearly related to precipitation and PE than other indices, such as those of Thornthwaite (1948) and Budyko (1955), which are computed as ratios of precipitation and PE.

In addition to annual PMPE, sub-annual indices of moisture conditions also are examined. On a monthly basis, PMPE can be positive or negative. Positive values of monthly PMPE indicate water that is in excess of the monthly climatic demand for water. This water, referred to as surplus, eventually becomes runoff (Legates \& Mather 1992). Summing surplus within a year provides a reasonable estimate of annual runoff (Wolock \& McCabe 1999a). Negative values of monthly PMPE indicate a deficit to meet the climatic demand for water. The annual sum of monthly deficits is an estimate of the amount of irrigation needed to grow plants at an optimum level (Legates \& Mather 1992). Annual surplus and annual deficit, then, provide estimates of moisture conditions that are directly related to important water resources or water resource needs, namely streamflow and irrigation demand.

Computation of PMPE, annual surplus, and annual deficit requires an estimate of PE. Two commonly used PE equations are the Thornthwaite (Thornthwaite 1948, Mather 1978) and Hamon (Hamon 1961) equations. The Thornthwaite PE equation has been used for a number of hydroclimate studies (Mather 1978). This equation, however, generally overestimates PE during summer months and underestimates PE during winter months (McCabe 1989). The Hamon PE equation (Hamon 1961) is similar to the Thornthwaite equation, but the Hamon equation provides more reliable estimates of PE during the winter and summer months than does the Thornthwaite equation. Vorosmarty et al. (1998) performed a comparison of various PE equations, including those of Hamon and Thornthwaite. Their results indicated that biases in PE estimates using the Hamon equation were smaller than those that resulted from using the Thornthwaite equation. Based on the Vorosmarty et al. (1998) results, the Hamon equation was chosen to compute PE for this study. The Hamon equation is

$$
\mathrm{PE}_{\text {Hamon }}=0.1651 d L W_{t}
$$


where $\mathrm{PE}_{\text {Hamon }}$ is Hamon PE in millimeters $(\mathrm{mm})$ per month, $d$ is the number of days in a month, $L$ is the mean monthly hours of daylight in units of $12 \mathrm{~h}$, and $W_{t}$ is a saturated water vapor density term calculated by

$$
W_{t}=4.95 \mathrm{e}^{0.062 T}
$$

where $T$ is monthly mean temperature in degrees Celsius.

2.2. Climate data. Monthly temperature and precipitation data for the 344 climate divisions in the conterminous US were used to compute PMPE, annual surplus, and annual deficit. The climate divisions represent regions within states that are, as nearly as possible, climatically homogeneous (Karl \& Riebsame 1984). In addition, the data for the climate divisions have been corrected for time-of-observation bias (Karl et al. 1986). Although extreme climatic variations can occur in areas of complex terrain, such as the mountainous areas of the western US, standardized departures of temperature and precipitation from normal are spatially consistent within a climate division (Karl \& Riebsame 1984). Monthly temperature and precipitation data for the years 1895-1999 were used to compute and examine trends in PMPE, annual surplus, and annual deficit, and data for the period 1961-1990 were used to represent current climatic conditions for temperature sensitivity studies.

2.3. Data analysis. Monthly temperature data for each of the climate divisions were used to compute monthly PE (using the Hamon equation) for the years 1895-1999. For each climate division, the monthly PE values were summed to generate time series of annual PE. Monthly precipitation data also were summed to compute time series of annual precipitation. The time series of annual PE and precipitation were subsequently used to compute annual PMPE for each climate division.

The monthly temperature and precipitation data also were used to compute time series of monthly PMPE. For each year, the sum of positive monthly PMPE was derived to determine annual surplus, and negative values were summed to produce annual deficit. (Because annual deficit is a negative value, high annual deficit is indicated by large negative numbers and low annual deficit is indicated by small negative numbers.)

Trends in the time series of PMPE, annual surplus, and annual deficit were examined using Kendall's tau statistic (Hirsch et al. 1982, Press et al. 1986). Kendall's tau measures the strength of a monotonic relation between 2 variables. The rationale for using Kendall's tau statistic is that it is a non-parametric statistic. In general, non-parametric statistics are less sensitive to outliers in the data compared to parametric statistics such as the Pearson correlation coefficient. Also, Kendall's tau can be appropriately used to detect non- linear monotonic trends in addition to linear trends (Press et al. 1986).

To examine the sensitivity of PMPE, annual surplus, and annual deficit in various regions of the US to increasing temperature, observed monthly temperature for each climate division was increased by $4^{\circ} \mathrm{C}$. PMPE, annual surplus, and annual deficit were computed for the 1961-1990 period using historical data, and then recomputed for the same period using the modified temperature data. Differences in mean PMPE, annual surplus, and annual deficit between the values generated using the observed and the modified temperature data were computed and mapped.

A uniform change in temperature was chosen for this study in order to focus on the sensitivity of moisture conditions to increased temperatures. Simulated changes in climate from general circulation models (GCMs) were not used because of the unreliability of GCM simulations and the discrepancies between GCM-simulated climates from different models (Wolock \& McCabe 1999b). To understand the hydrologic response to climate change, prescribed uniform changes in climate are often used (Schaake 1990, Nash \& Gleick 1991, 1993, McCabe \& Hay 1995, Gleick 2000). Prescribed climate changes are not intended to represent forecasts of future climate, rather they represent a defined alteration in climate that can be used to evaluate the sensitivity of natural systems to the specified climate change.

\section{RESULTS AND DISCUSSION}

Mean PMPE values for the 1961-1990 period illustrate relative moisture conditions across the conterminous US (Fig. 1A). Mean PMPE is positive for most climate divisions in the eastern US. In contrast, PMPE values are negative for most climate divisions in the western US, with the exception of some climate divisions in the northwestern US and the northern Rocky Mountains. The year-to-year variability in PMPE (i.e. standard deviation of PMPE) for each climate division is highly correlated with mean PMPE ( $\mathrm{r}=0.67$, Fig. 1B).

\subsection{Historical trends in PMPE}

During the 1895-1999 period, the majority of statistically significant trends in PMPE have been increasing trends, although only a few have been statistically significant (Fig. 2A, Table 1). (Kendall's tau values greater than 0.13 or less than -0.13 are significant at a $95 \%$ confidence level.) Most of the significant increasing trends have primarily occurred in the eastern US. A few significant decreasing trends, however, have 


\section{A. Mean PMPE (millimeters)}

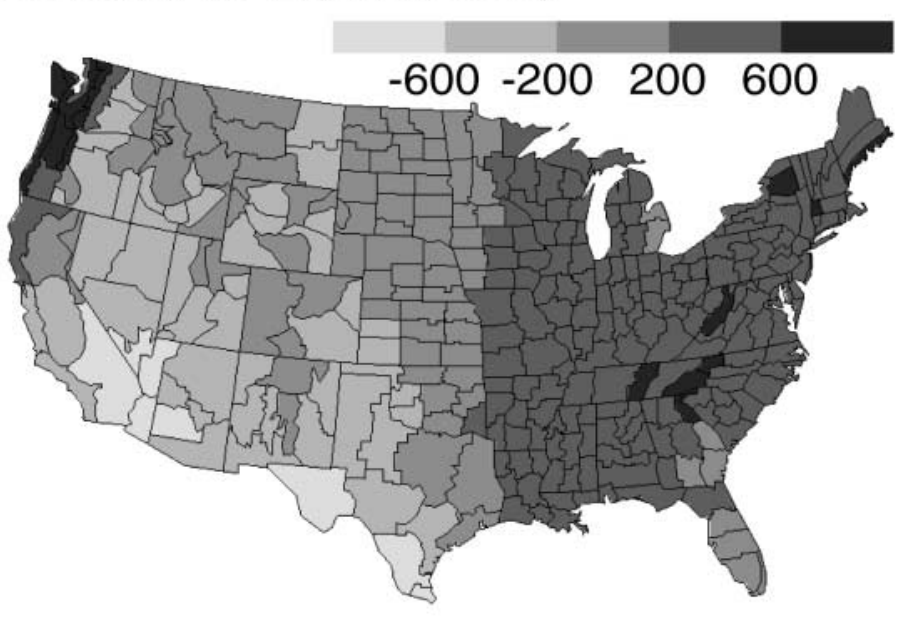

\section{B. PMPE Standard Deviation (millimeters)}

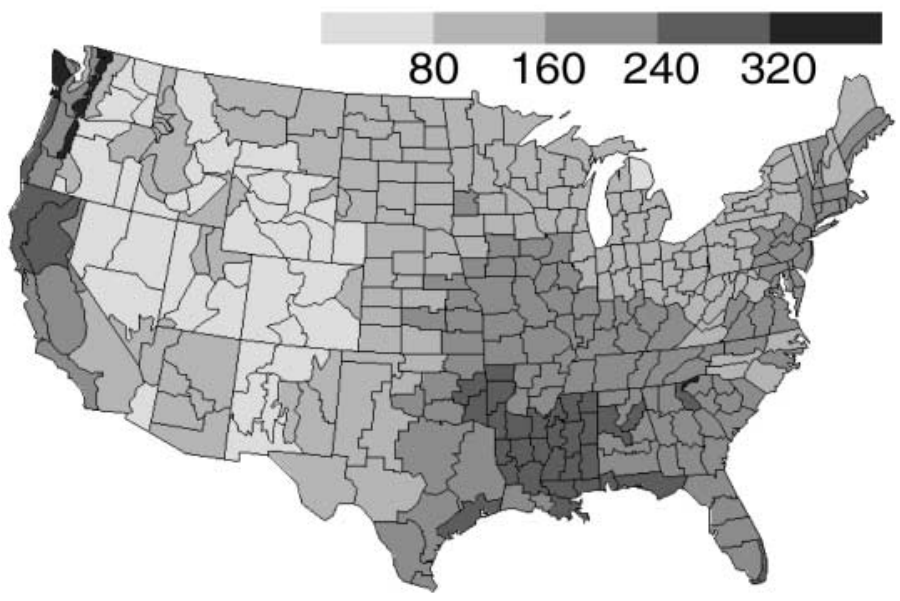

Fig. 1. (A) Mean and (B) standard deviation of annual precipitation minus annual potential evapotranspiration (PMPE) for the climate divisions of the conterminous US, 1961-1990

occurred in parts of the western US and in the extreme Northeast. To examine the contribution of trends in precipitation and PE to trends in PMPE, Kendall's tau was used to identify trends in the annual time series of precipitation and $\mathrm{PE}$ for each climate division (Fig. 2B,C, Table 1). The trends for precipitation and $\mathrm{PE}$ for each climate division were then compared with the trends for PMPE. Although there have been more statistically significant trends in PE than in precipitation, the trends in precipitation explain more of the trends in PMPE than do the trends in PE. The correlation (Pearson correlation) between Kendall's tau values for precipitation and those for PMPE is 0.95, whereas the correlation between Kendall's tau values for PE and those for PMPE is -0.46 .
A time series of mean PMPE values for the conterminous US was computed by averaging (on an equal area basis) the annual PMPE values for each climate division (Fig. 3). This time series illustrates the general tendency of moisture conditions for the entire conterminous US. The time series indicates various periods when mean PMPE for the conterminous US was below zero for an extended period of time (e.g. the 1930s and the 1950s). These periods represent significant drought episodes in the US. However, there also have been periods of extended wet conditions, especially

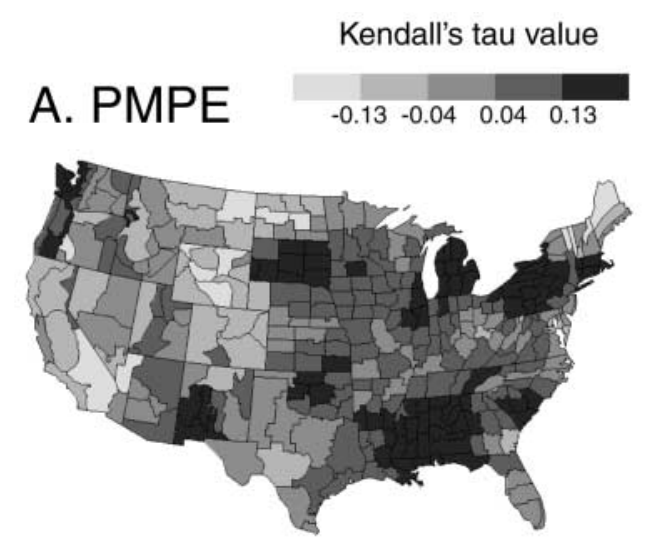

B. Precipitation
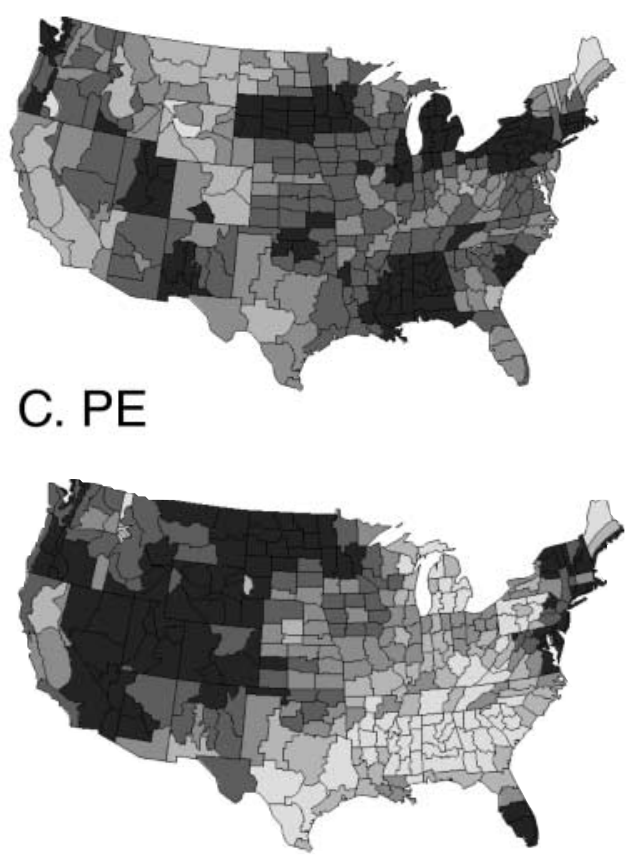

Fig. 2. Values of Kendall's tau statistic for (A) annual PMPE values, (B) precipitation, and (C) potential evapotranspiration (PE) for the climate divisions of the conterminous US, 1895-1999. Kendall's tau values greater than 0.13 or less than -0.13 indicate significant trends at the $95 \%$ confidence level 
Table 1. (A) Number of climate divisions and (B) fraction of area of the conterminous US with significant trends (at a 95\% confidence level) in annual precipitation minus potential evapotranspiration (PMPE), precipitation (P), potential evapotranspiration (PE), annual surplus (S), and annual deficit (D). Trends were determined using Kendall's tau

\begin{tabular}{|lcccc|}
\hline & $\begin{array}{c}\text { Negative } \\
\text { trends }\end{array}$ & $\begin{array}{c}\text { No } \\
\text { trends }\end{array}$ & $\begin{array}{c}\text { Positive } \\
\text { trends }\end{array}$ & $\begin{array}{c}\text { Total } \\
\text { trends }\end{array}$ \\
\hline (A) Number of climate divisions & & \\
PMPE & 15 & 234 & 95 & 110 \\
P & 7 & 227 & 110 & 117 \\
PE & 70 & 174 & 100 & 170 \\
S & 13 & 211 & 120 & 133 \\
D & 26 & 281 & 37 & 63 \\
& & & & \\
(B) Fraction & of area of the conterminous US & \\
PMPE & 0.06 & 0.75 & 0.20 & 0.26 \\
P & 0.01 & 0.74 & 0.25 & 0.26 \\
PE & 0.17 & 0.51 & 0.32 & 0.49 \\
S & 0.04 & 0.71 & 0.25 & 0.29 \\
D & 0.08 & 0.83 & 0.09 & 0.17 \\
& & & & \\
\hline
\end{tabular}

since the mid-1960s. An analysis of this time series using Kendall's tau indicates a statistically significant (at a 95\% confidence level) increase in mean PMPE for the conterminous US. The increase in mean PMPE for the conterminous US since the 1960s was discussed by Idso \& Balling (1992). They noted an increasing trend in mean Palmer Drought Severity Index (PDSI) values for the conterminous US since the late 1950s, and primarily positive values (wet conditions) of the PDSI since the mid-1960s. They suggested that the shift to wetter conditions is related to increasing sulfur dioxide $\left(\mathrm{SO}_{2}\right)$ emissions since the mid-1950s. The increased $\mathrm{SO}_{2}$ concentration of the atmosphere is hypothesized to increase cloud cover and rainfall (Albrecht 1989, Wigley 1989), and thus surface moisture conditions.

\subsection{Observed annual surplus and annual deficit}

Mean annual surplus has a spatial distribution that is similar to that of mean annual PMPE $(r=0.92$, Figs $1 \mathrm{~A} \&$ 4A). Mean annual surplus is high in the eastern US (particularly in the Southeast) and the northern Pacific coast; mean annual surplus is low for most of the western US. As with PMPE, mean annual surplus and the standard deviation of annual surplus are highly correlated ( $\mathrm{r}=0.90$, Fig. 4B). In addition, the spatial distribution of mean annual surplus is similar to that of mean annual runoff (not shown). For example, the correlation between mean annual surplus computed for 1951-1980 and observed mean annual runoff computed by Gebert et al. (1987) for the same time period is 0.94 .

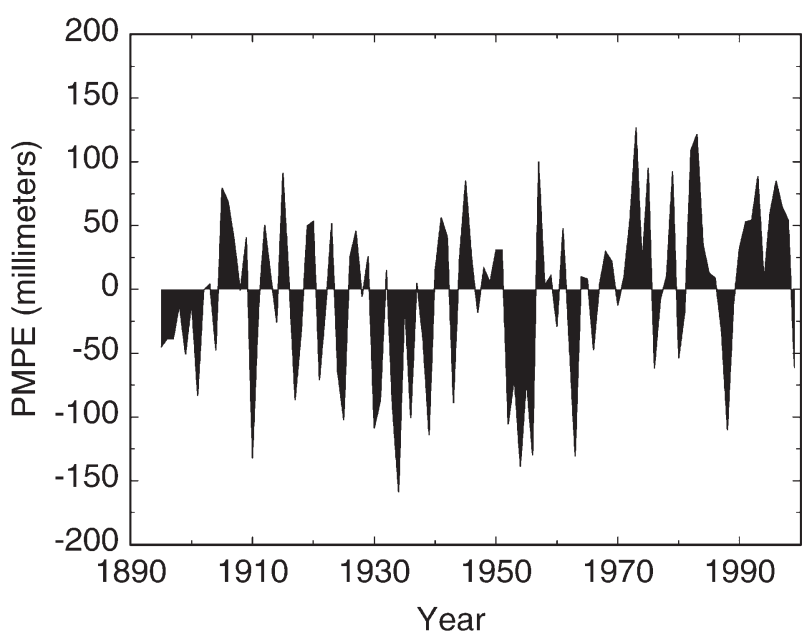

Fig. 3. Time series of area-weighted average values of annual PMPE, 1895-1999

Mean annual deficit also is highly correlated with mean annual PMPE ( $\mathrm{r}=0.78$, Figs $1 \mathrm{~A} \& 4 \mathrm{C})$. The largest mean annual deficit (most negative) is found in the southwestern US, and the smallest mean annual deficit (least negative) is found in the northeastern US. The spatial pattern of mean annual deficit is not highly correlated with mean annual surplus (Fig. 4A); however, there is a statistically significant correlation (at a $95 \%$ confidence level) between the spatial distributions of mean annual deficit and mean annual surplus $(\mathrm{r}=0.49)$. This correlation reflects the general tendency for dry areas to be associated with large mean annual deficit (large negative values) and small mean annual surplus, and wet areas to be associated with small mean annual deficit (small negative values) and large mean annual surplus. The relative weakness of the correlation is due in part to the fact that annual surplus and annual deficit are associated with different seasons. For most locations, annual surplus primarily results from conditions during cool months (the winter season) and annual deficit results from conditions during warm months (the summer season) (Fig. 5). Among the climate divisions, the median percentage of the annual surplus generated during the winter months was about $60 \%$, and the median percentage of the annual deficit from the summer months was about $80 \%$.

\subsection{Historical trends in annual surplus and annual deficit}

Trends in annual surplus and annual deficit suggest that the eastern US has become slightly wetter and the western US has become slightly drier during the period 1895-1999 (Fig. 6A,B). There have been more 


\section{A. Mean Surplus (millimeters)}

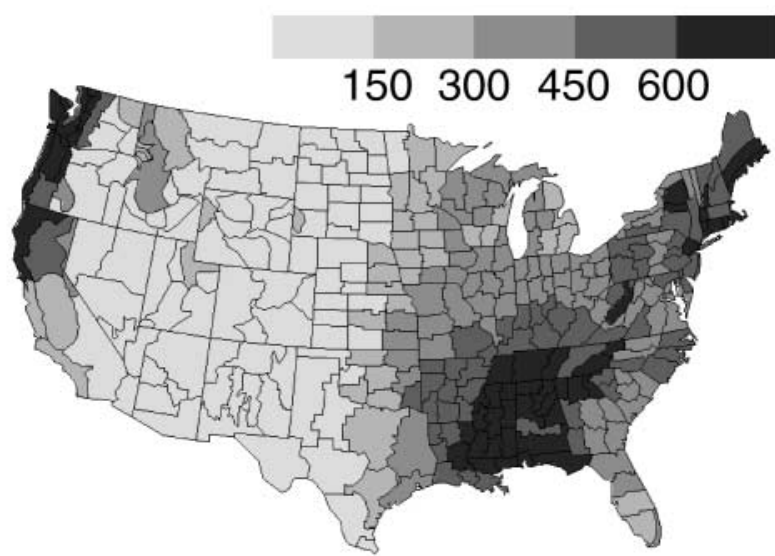

\section{Mean Deficit (millimeters)}

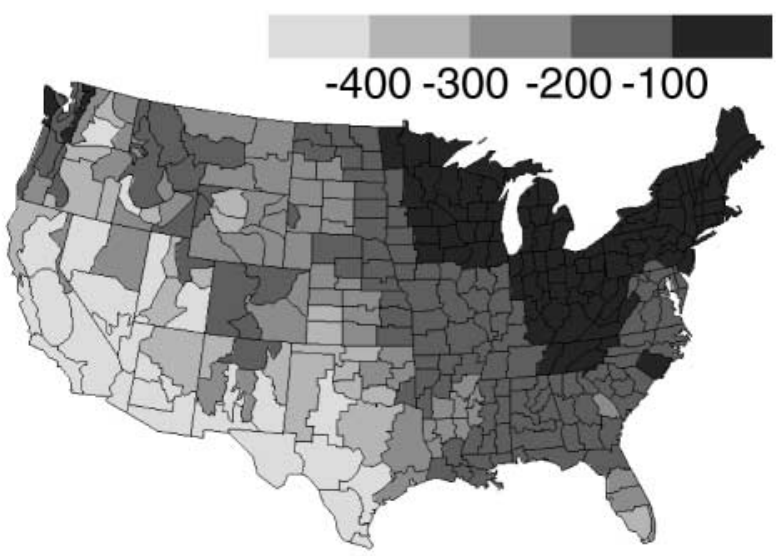

\section{B. Surplus Standard Deviation (millimeters)}

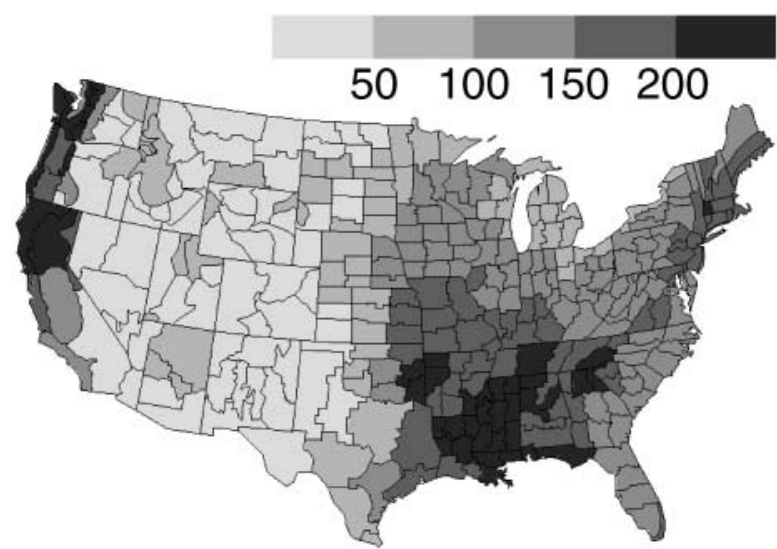

\section{Deficit Standard Deviation (millimeters)}

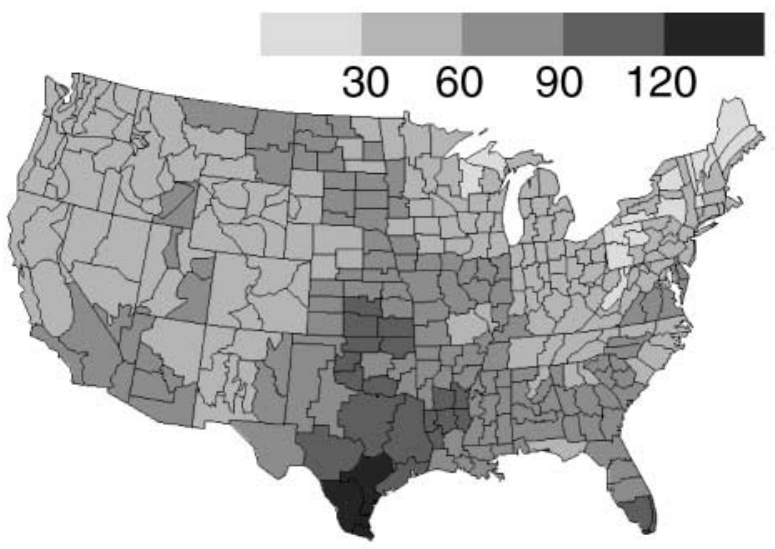

Fig. 4. (A) Mean annual surplus, (B) standard deviation of annual surplus, (C) mean annual deficit, and (D) standard deviation of annual deficit for the climate divisions of the conterminous US, 1961-1990

significant trends in annual surplus than in annual deficit, and the significant trends in annual surplus have primarily been increasing trends in the eastern US (Fig. 6A,B, Table 1). These results suggest that not only has the eastern US become wetter, but because more trends are found in annual surplus rather than annual deficit, these changes mostly have taken place during the cool months when precipitation exceeds PE.

The annual surplus and deficit values for each climate division were averaged on an equal area basis to generate time series of annual surplus and deficit for the conterminous US (Fig. 7A,C). To more easily compare the annual surplus and annual deficit time series and to more easily identify wet and dry periods, the time series were standardized by subtracting the re- spective long-term means and dividing by the respective long-term standard deviations (Fig. 7B,D).

The time series of annual surplus indicates a slight increase in annual surplus during 1895-1999 (Fig. 7A,B). Kendall's tau statistic indicates a significant (at a $95 \%$ confidence level) trend in annual surplus for the conterminous US as a whole. This is consistent with the trend found in mean annual PMPE (Fig. 3). In contrast, the time series of annual deficit does not indicate a statistically significant trend (Fig. 7C,D).

These results suggest that the conterminous US as a whole has become wetter since 1895, and this trend most likely is due to wetter conditions during the cool season months. An analysis of Kendall's tau values in winter (October through March) precipitation and PE 


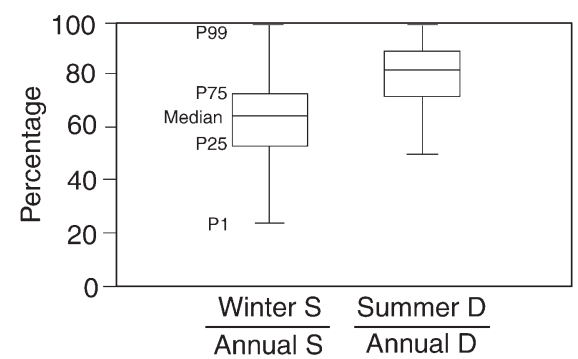

Fig. 5. Boxplots of the percentage of annual surplus (S) represented by winter (October through March) surplus, and the percentage of annual deficit (D) represented by summer (April through September) deficit. P1: 1st percentile value; P25: 25th percentile value; P75: 75th percentile value; P99: 99th percentile value

\section{A. Surplus}

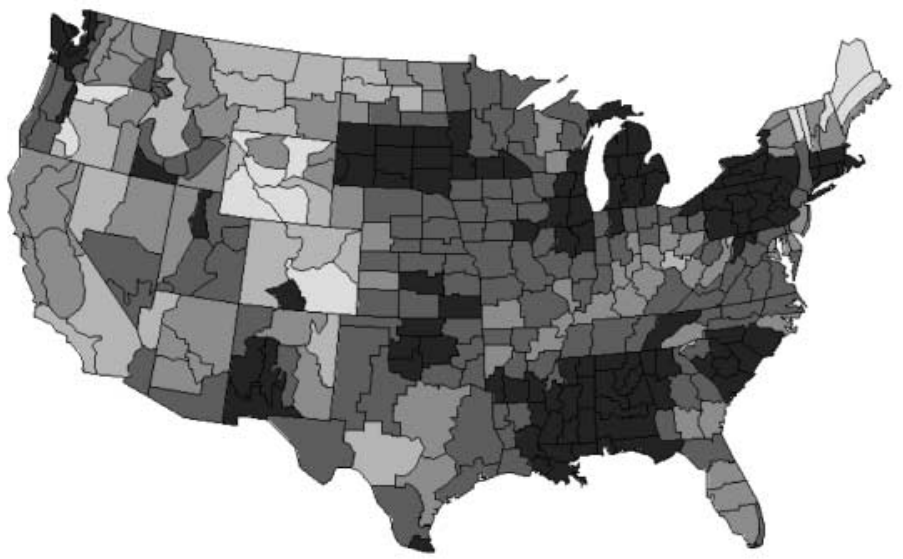

Kendall's tau value

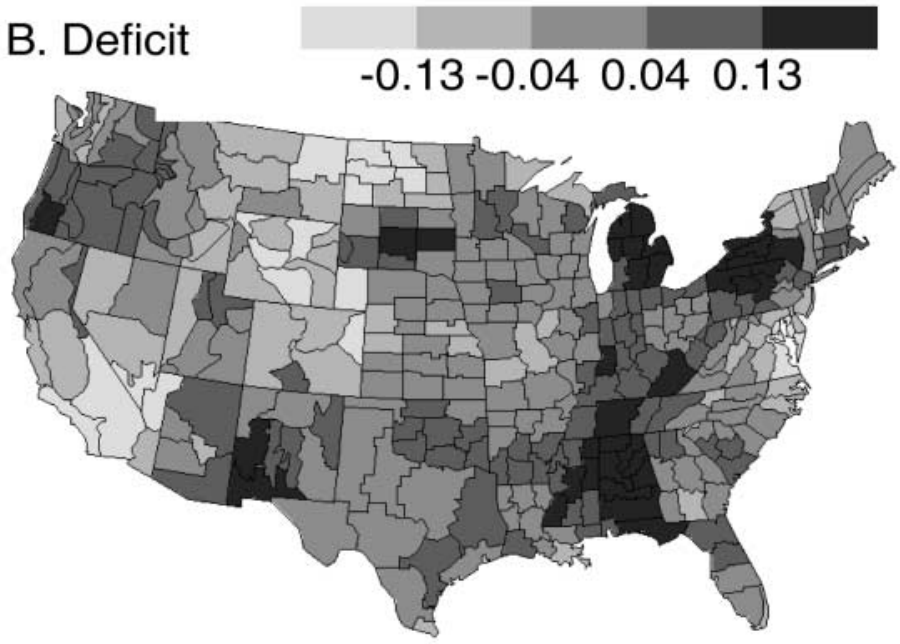

Fig. 6. Values of Kendall's tau statistic for (A) annual surplus and (B) annual deficit for the climate divisions of the conterminous US, 1895-1999. Kendall's tau values greater than 0.13 or less than -0.13 indicate significant trends at the $95 \%$ confidence level
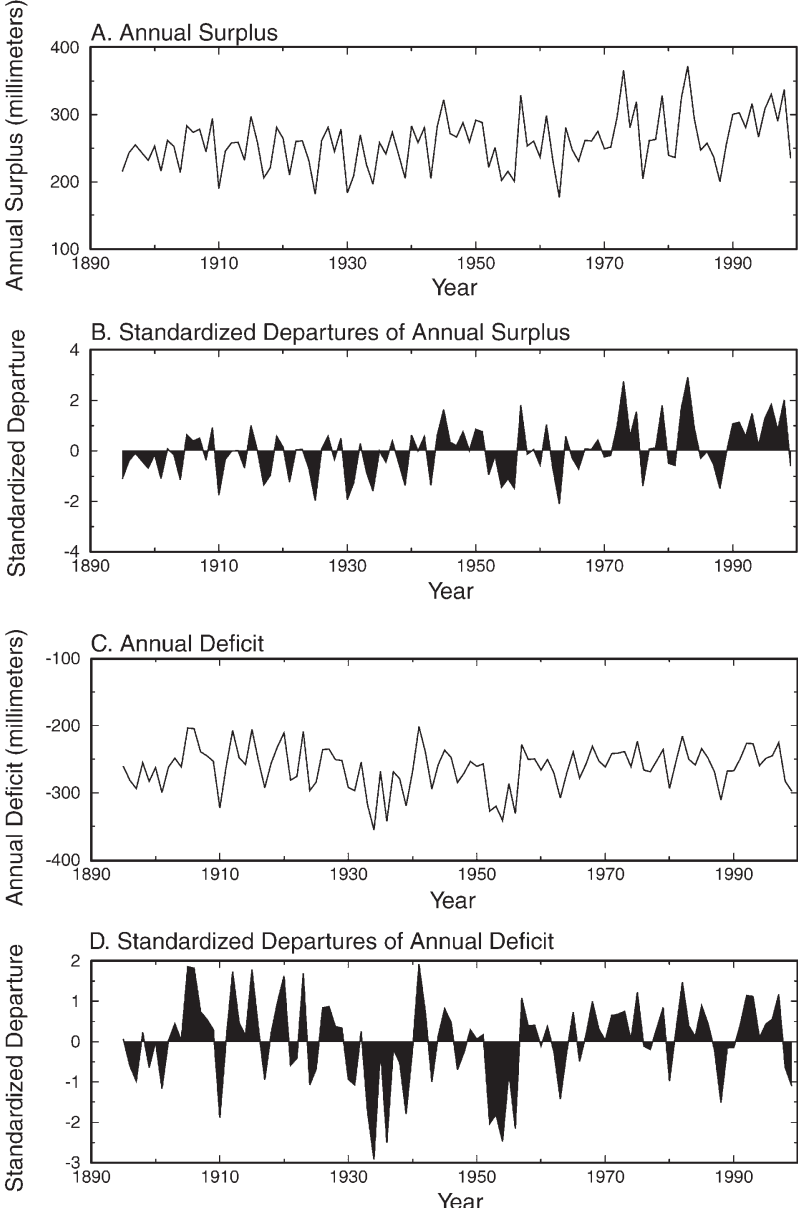

Fig. 7. Time series of area-weighted average values for (A) annual surplus, (B) standardized departure of annual surplus, (C) annual deficit, and (D) standardized departure of annual deficit for the conterminous US, 1895-1999. The standardized departure is computed by subtracting the long-term mean and dividing by the long-term standard deviation

indicates that the trends in annual surplus are a result of trends in winter precipitation $(\mathrm{r}=0.86)$. The correlation between Kendall's tau values in annual surplus and Kendall's tau values in winter PE is only -0.17 .

\subsection{Effects of increased temperature}

The change in mean annual PMPE (based on the 1961-1990 period) resulting from a $4^{\circ} \mathrm{C}$ increase in monthly temperatures (Fig. 8) is greatest for the warmest locations of the conterminous US and least for the coolest locations. (The correlation between the change in PMPE and the mean annual temperature for the climate divisions is -0.98.) The change in PMPE is directly related to the change in mean annual $\mathrm{PE}$ (Fig. 9). In warm regions, the $4^{\circ} \mathrm{C}$ change in temperature results in a larger increase in $\mathrm{PE}$ than the same 


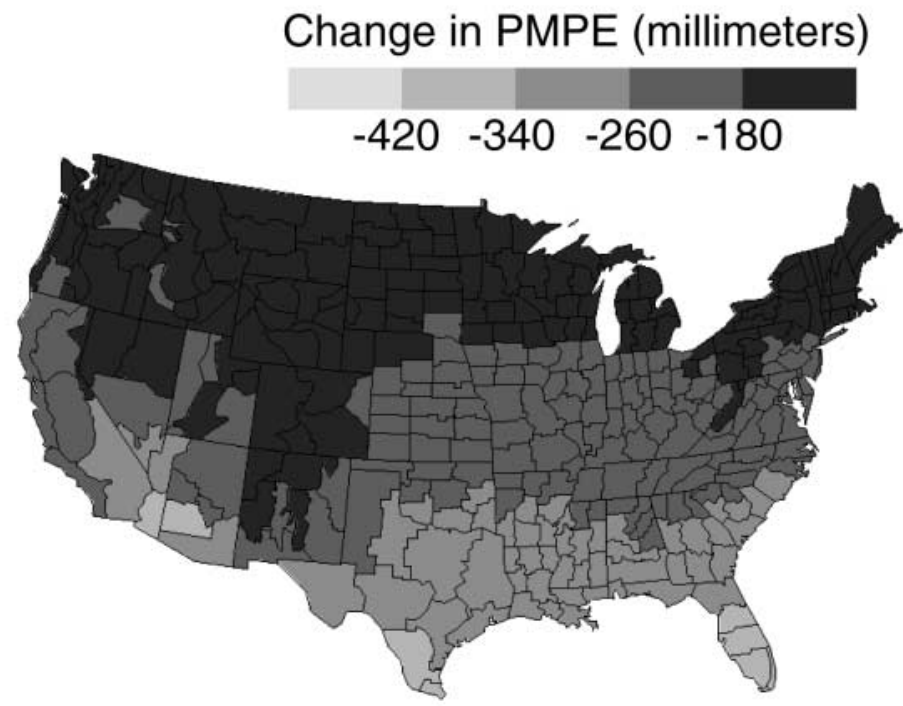

Fig. 8. Change in PMPE given a $4^{\circ} \mathrm{C}$ increase in temperature

temperature change in cool regions (Fig. 10). This is because of the relation between temperature and the saturation vapor pressure of air. For warm air, increases in temperature result in larger increases in the amount of water that can be held in the atmosphere than occur for cool air. Thus, for warm regions, an increase in temperature results in a relatively large increase in the climatic demand for water (PE) and a relatively large decrease in PMPE.

Changes in mean annual surplus for a $4^{\circ} \mathrm{C}$ increase in temperature were greatest in the wettest regions of the conterminous US (e.g. the southeastern US and the Pacific Northwest, Fig. 11A). Changes in mean annual surplus were least for the dry regions of the country

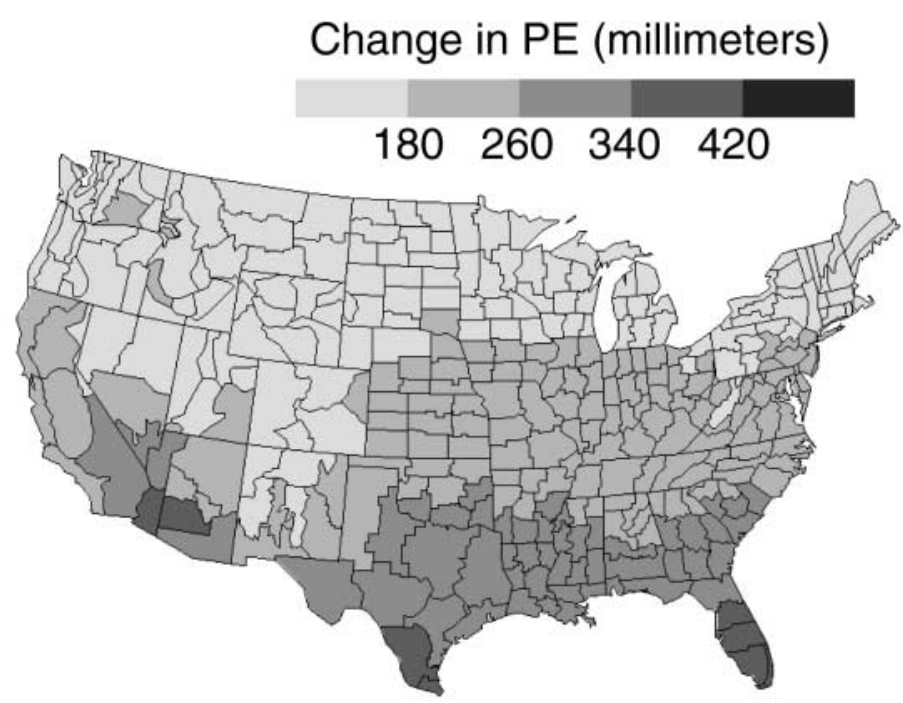

Fig. 9. Changes in annual PE for the climate divisions of the conterminous US given a $4^{\circ} \mathrm{C}$ increase in temperature (most of the western US). In dry regions, annual surplus is low or close to zero; therefore, increased PE (resulting from increased temperature) cannot result in a large change in annual surplus. In wet regions, annual surplus is large and any increase in PE will result in a proportional decrease in annual surplus. In addition, the warmest and most humid regions experience the greatest decreases in annual surplus because of the high sensitivity of PE to temperature in warm regions compared to cool regions.

Changes in mean annual deficit for a $4^{\circ} \mathrm{C}$ increase in temperature (Fig. 11B) reflect the pattern of increases in $\mathrm{PE}$ (Fig. 9). Large increases in PE result in large increases in annual deficit. The correlation between increases in PE and changes in annual deficit is -0.72 . (The correlation coefficient is negative because large increases in annual deficit are large negative numbers.) In addition, changes in annual deficit are larger for dry regions than for wet regions. This is because in dry regions there is little or no annual surplus available to counteract increases in PE.

\subsection{Trend-detection sensitivity to increases in temperature}

The ability to detect a trend in PMPE, annual surplus, or annual deficit given a specified increase in temperature is dependent on the magnitude of the temperature-induced change in the moisture condition index and the year-to-year variability of the moisture index. The magnitude of the change in the moisture index relative to its year-to-year variability is analogous to a signal-to-noise ratio (McCabe \& Wolock 1997); the larger the change relative to the variability, the greater the trend-detection sensitivity of the moisture index to increases in temperature. Based on this

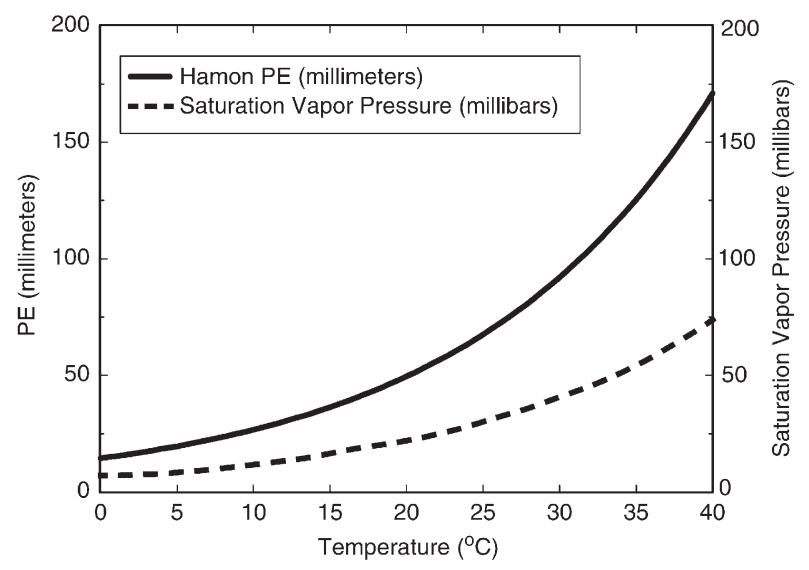

Fig. 10. Effects of temperature on PE computed using the Hamon equation and saturation vapor pressure 


\section{A. Change in Surplus (millimeters)}

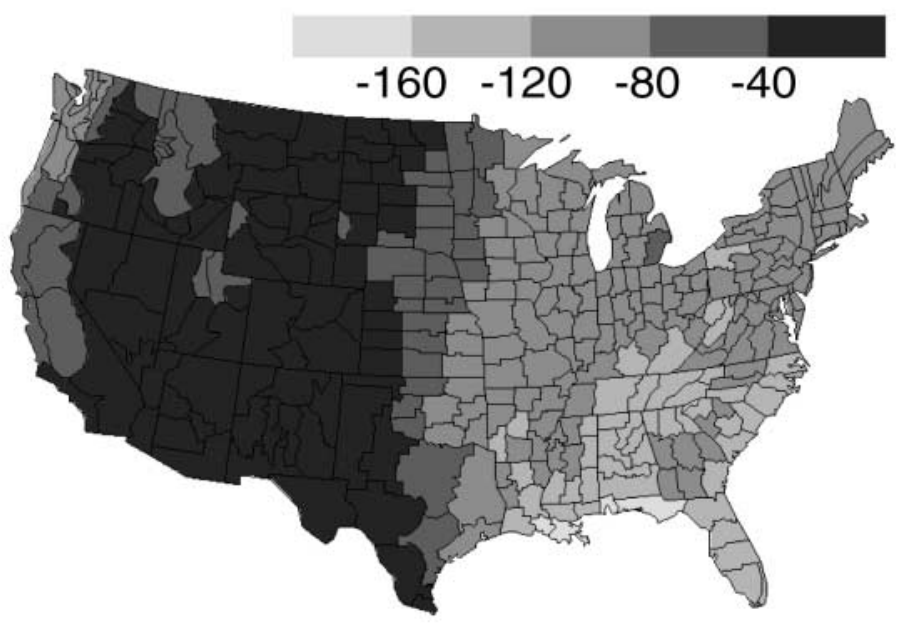

B. Change in Deficit (millimeters)

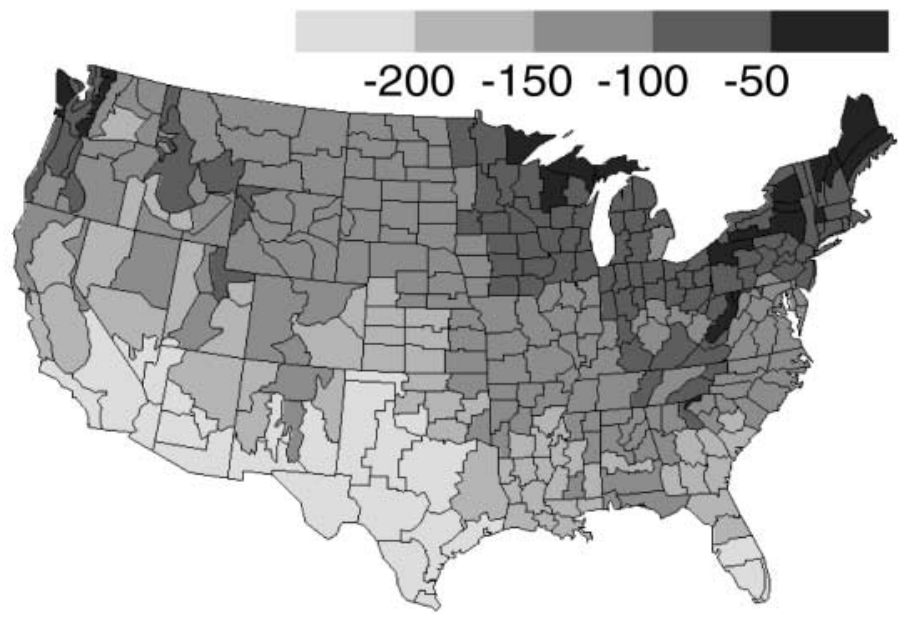

Fig. 11. Changes in (A) annual surplus and (B) annual deficit for the climate divisions of the conterminous US given a $4{ }^{\circ} \mathrm{C}$ increase in temperature

concept, an index of trend-detection sensitivity for PMPE, annual surplus, and annual deficit to increased temperature (Figs 12 \& 13) was computed as the change in the variable (the signal) divided by the yearto-year standard deviation of the variable (the noise).

The trend-detection sensitivity of PMPE to a $4^{\circ} \mathrm{C}$ increase in temperature is greatest (in magnitude) for locations in some parts of the western US and is lowest for locations in the Mississippi River Valley, New England, and the Pacific coast (Fig. 12). This spatial pattern of trend-detection sensitivity reflects the combination of changes in PMPE from a $4^{\circ} \mathrm{C}$ warming (the signal, Fig. 8) and year-to-year variability (the noise) in PMPE (Fig. 1B). The greatest trend-detection sensitivity occurs where the change in PMPE relative to its variability is highest.
The pattern of trend-detection sensitivity for annual surplus is different from that for PMPE. The greatest trend-detection sensitivity for changes in annual surplus to increased temperature are scattered in several parts of the country, and the areas with the smallest trend-detection sensitivity of annual surplus are in California and some parts of the southwestern US (Fig. 13A). This pattern reflects the combination of the change in annual surplus resulting from the $4{ }^{\circ} \mathrm{C}$ warming (Fig. 11A) and the standard deviation of annual surplus (Fig. 4B).

The trend-detection sensitivity of annual deficit to increases in temperature is greatest in the southwestern US and least in the central and northeastern US, the extreme northwestern US, and parts of the northern Rocky mountains (Fig. 13B). This spatial pattern is the result of the change in annual deficit (Fig. 11B) and its standard deviation (Fig. 4D).

The numerical experiments of prescribed climate change on moisture indices presented in this paper did not include the effects of changes in precipitation. Changes in precipitation were not included because (1) the magnitude and direction of changes in precipitation resulting from global warming are very uncertain, and (2) the focus of this study is on the effects of increasing temperature on moisture conditions. If precipitation decreases in an area, then the effects of increased temperature on moisture conditions will be exacerbated. In contrast, if precipita-

\section{Change in PMPE/PMPE Standard Deviation}

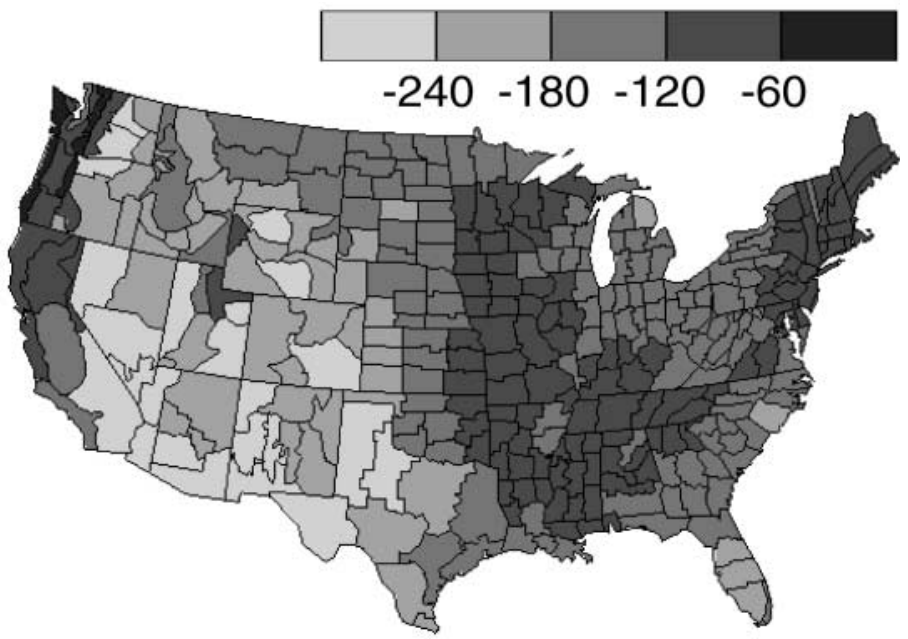

Fig. 12. Ratio of the change in annual PMPE to the standard deviation of PMPE for the climate divisions of the conterminous US. The changes in PMPE were computed for a $4^{\circ} \mathrm{C}$ increase in temperature from 1961-1990 conditions and the standard deviations of PMPE was computed using data for 1961-1990 


\section{A. Change in Surplus/Surplus Standard Deviation}

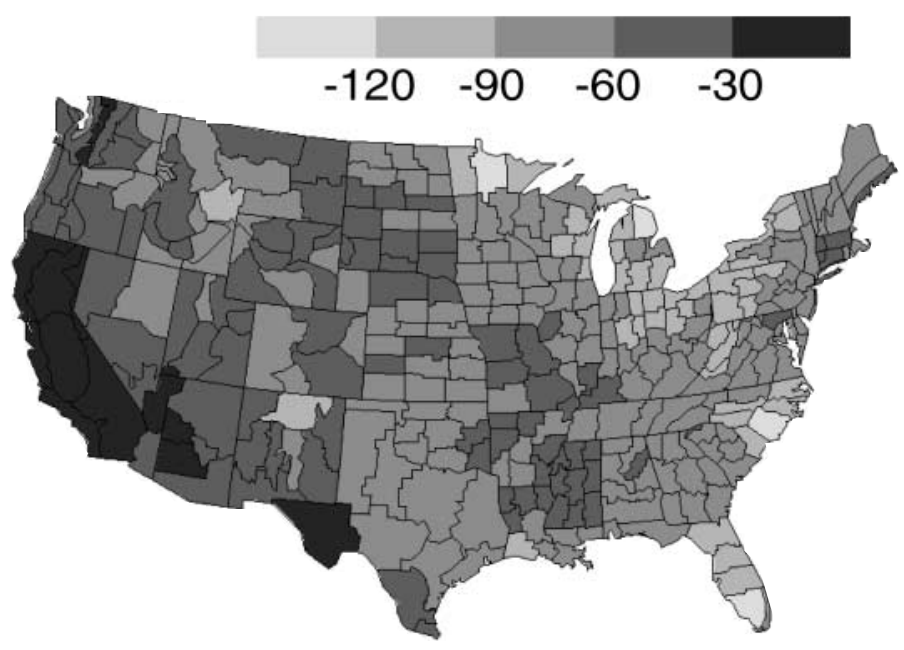

B. Change in

Deficit/Deficit Standard Deviation

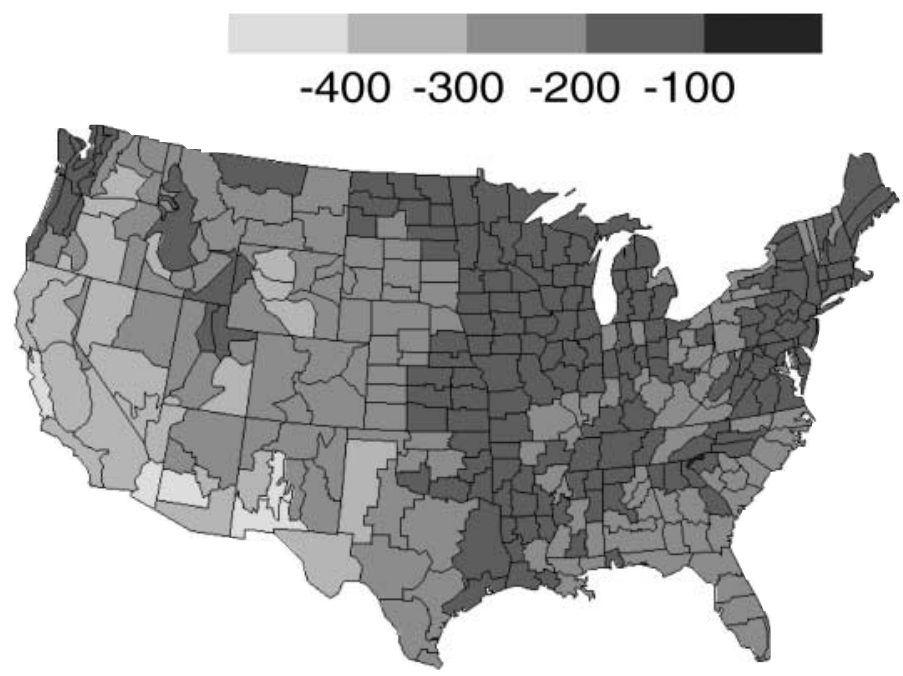

Fig. 13. (A) Ratio of the change in annual surplus to the standard deviation of annual surplus, and (B) ratio of the change in annual deficit to the standard deviation of annual deficit for the climate divisions of the conterminous US. The changes in surplus and deficit were computed for a $4^{\circ} \mathrm{C}$ increase in temperature from 1961-1990 conditions and the standard deviations of surplus and deficit were computed using data for 1961-1990

tion increases, then the effects of increased temperature will be mitigated. In general, proportional changes in precipitation will be needed to offset the effects of increases in PE resulting from increased temperature.

\section{CONCLUSIONS}

In this study, indices of climatic moisture conditions (PMPE, annual surplus, and annual deficit) were used to examine historical trends in moisture conditions in the conterminous US and the effects of an increase in temperature of $4^{\circ} \mathrm{C}$ on moisture conditions. Results indicate that since 1895 there have been statistically significant increases in PMPE and annual surplus in the eastern US and for the conterminous US as a whole. There have been a few statistically significant trends in annual deficit, but for the conterminous US as a whole there has not been a trend in annual deficit.

For a prescribed $4^{\circ} \mathrm{C}$ increase in temperature, decreases in PMPE are greatest for the warmest locations in the conterminous US. This is due to the relation between temperature and the saturation vapor pressure of air. For high temperature areas, the change in the saturation vapor pressure for a specified increase in temperature is larger than for low temperature areas. Thus, for warm regions an increase in temperature results in a larger increase in PE than for cool regions. Changes in annual surplus for increased temperature were greatest in the humid regions of the conterminous US. In these regions, increases in PE resulting from increased temperature result in proportional decreases in annual surplus. In dry regions, annual surplus is low (or close to zero), and therefore only small decreases in annual surplus can occur as a result of increased temperature. Changes in annual deficit were greatest for dry regions. This is because in dry regions there is little water available to counteract increases in PE.

An analysis of the trend-detection sensitivity of the moisture-condition indices to a $4^{\circ} \mathrm{C}$ increase in temperature was performed by comparing the resultant changes in PMPE, annual surplus, and annual deficit to the respective standard deviations of these indices. Results of this analysis indicated that the trend-detection sensitivity of PMPE and annual deficit to increased temperature was greatest in the dry regions of the western US. The trend-detection sensitivity of annual surplus to increased temperature did not show a clear pattern, although the sensitivity was lowest in California and other parts of the western US.

\section{LITERATURE CITED}

Albrecht BA (1989) Aerosols, cloud microphysics, and functional cloudiness. Science 245:1227-1230

Ayers MA, Wolock DM, McCabe GJ, Hay LE, Tasker GD (1994) Sensitivity of water resources in the Delaware River basin. US Geological Survey Water-Supply Paper 2422, US Geological Survey, Reston, VA

Budyko MI (1955) Atlas of the heat balance. Gridometeoizdat, Leningrad 
Budyko MI (1974) Climate and life. Academic Press, San Diego, CA

Feddema JJ, Mather JR (1992) Hydrological impacts of global warming over the United States. In: Majumdar SK, Kalkstein LS, Yarnal B, Miller EW, Rosenfeld LM (eds) Global climate change: implications, challenges and mitigation measures. The Pennsylvania Academy of Science, Easton, PA, p 50-62

Gebert WA, Graczyk DJ, Krug WR (1987) Average annual runoff in the United States, 1951-1980. Hydrol Invest Atlas HA-710, US Geological Survey, Reston, VA

Gleick PH (1987) Regional hydrologic consequences of increases in atmospheric $\mathrm{CO}_{2}$ and other trace gases. Clim Change 10:137-161

Gleick PH (1989) Climate change, hydrology, and water resources. Rev Geophys 27:329-344

Gleick PH (2000) Water: the potential consequences of climate variability and change. The report of the water sector assessment team of the national assessment of the potential consequences of climate variability and change. Pacific Institute for Studies in Development, Environment, and Security, Oakland, CA

Hamon WR (1961) Estimating potential evapotranspiration. J Hydraul Div Proc Am Soc Civil Eng 87:107-120

Hirsch RM, Slack JR, Smith RA (1982) Techniques of trend analysis for monthly water quality data. Water Resour Res 18:107-121

Idso SB, Balling RC (1992) United States drought trends of the past century. Agric For Meteorol 20:279-284

Idso SB, Brazel AJ (1984) Rising atmospheric carbon dioxide concentrations may increase streamflow. Nature 312:51-53

Karl TR, Riebsame WE (1984) The identification of 10- to 20year temperature fluctuations and precipitation fluctuations in the contiguous United States. J Clim Appl Meteorol 23:950-966

Karl TR, Riebsame WE (1989) The impact of decadal fluctuations in mean precipitation and temperature on runoff: a sensitivity study over the United States. Clim Change 15:423-447

Karl TR, Williams CN, Young PJ, Wendland WM (1986) A model to estimate the time of observation bias associated with monthly mean maximum, minimum and mean temperatures for the United States. J Clim Appl Meteorol 25: $145-160$

Karl TR, Tarpley JD, Quayle RG, Diaz HF, Robinson DA, Bradley RS (1989) The recent climate record: what it can and cannot tell us. Rev Geophys 27:405-430

Legates DR, Mather JR (1992) An evaluation of the average annual global water balance. Geogr Rev 82:253-267

Lettenmaier DP, Gan TY (1990) Hydrologic sensitivities of the Sacramento-San Joaquin River basin, California, to global warming. Water Resour Res 26:69-86

Lettenmaier DP, Sheer DP (1991) Climatic sensitivity of California water resources. J Water Resour Planning Manage 117:108-125

Lins HF, Slack JR (1999) Streamflow trends in the United States. Geophys Res Lett 26:227-230

Mather JR (1978) The climatic water budget in environmental analysis. Lexington Books, Lexington, MA

Mather JR, Feddema J (1986) Hydrologic consequences of increases in trace gases and $\mathrm{CO}_{2}$ in the atmosphere. In: Effects of changes in stratospheric ozone and global climate, Vol 3. Climate change. US Environmental Protection Agency, Washington, DC, p 251-271
McCabe GJ (1989) A parabolic function to modify Thornthwaite estimates of potential evapotranspiration for the eastern United States. Phys Geogr 10:176-189

McCabe GJ, Ayers MA (1989) Hydrologic effects of climate change in the Delaware River basin. Water Resour Bull 25:1231-1242

McCabe GJ, Hay LE (1995) Hydrological effects of hypothetical climate change in the East River basin, Colorado. J Hydrol Sci 40:303-318

McCabe GJ, Wolock DM (1991) Detectability of the effects of a hypothetical temperature increase on the Thornthwaite moisture index. J Hydrol 125:25-35

McCabe GJ, Wolock DM (1992) Effects of climatic change and climatic variability on the Thornthwaite moisture index in the Delaware River basin. Clim Change 20:143-155

McCabe GJ, Wolock DM (1997) Climate change and the detection of trends in annual runoff. Clim Res 8:129-134

Milly PCD (1994) Climate, soil water storage, and the average annual water balance. Water Resour Res 30:2143-2156

Nash LL, Gleick PH (1991) Sensitivity of streamflow in the Colorado Basin to climatic changes. J Hydrol 125:221-241

Nash LL, Gleick PH (1993) The Colorado River basin and climatic change: the sensitivity of streamflow and water supply to variations in temperature and precipitation. US Environmental Protection Agency, EPA 230-R-93-009, Washington, DC

Nemec J, Schaake JS (1982) Sensitivity of water resources systems to climate variation. J Hydrol Sci 27:327-343

Press WH, Flannery BP, Teukolsky SA, Vetterling WT (1986) Numerical recipes. Cambridge University Press, Cambridge

Schaake JS (1990) From climate to flow. In: Waggoner PE (ed) Climate change and US water resources. John Wiley, New York, p 177-206

Solow AR (1987) Testing for climate change: an application of the two-phase regression model. J Clim Appl Meterol 26:1401-1405

Solow AR, Broadus JM (1989) On the detection of greenhouse warming. Clim Change 15:449-453

Thornthwaite CW (1948) An approach toward a rational classification of climate. Geogr Rev 38:55-94

Thornthwaite CW, Mather JR (1955) The water balance. Publications in Climatology, Laboratory of Climatology, Vol 8. Seabrook, NJ

Vorosmarty CJ, Federer CA, Schloss AL (1998) Potential evaporation functions compared on US watersheds: possible implications for global-scale water balance and terrestrial ecosystem modeling. J Hydrol 207:147-169

Wigley TML (1989) Possible climate change due to $\mathrm{SO}_{2}$ derived cloud condensation nuclei. Nature 338:365-367

Wigley TML, Jones PD (1985) Influences of precipitation changes and direct $\mathrm{CO}_{2}$ effects on streamflow. Nature 314:149-152

Willmott CJ, Feddema JJ (1992). A more rational climatic moisture index. Prof Geogr 44(1):84-88

Wolock DM, Hornberger GM (1991) Hydrological effects of changes in levels of atmospheric carbon dioxide. J Forecast 10:105-116

Wolock DM, McCabe GJ (1999a) Explaining spatial variability in mean annual runoff in the conterminous United States. Clim Res 11:149-159

Wolock DM, McCabe GJ (1999b) Estimates of runoff using water-balance and atmospheric general circulation models. J Am Water Res Assoc 35:1341-1350

Submitted: May 1, 2000; Accepted: May 8, 2001

Proofs received from author(s): December 14, 2001 